\title{
Heart rate variability and phantom pain in male amputees: Application of linear and nonlinear methods
}

\author{
Elena Sarabia Cachadiña, PhD $;^{1 *}$ Pablo Granados García, MSci; ${ }^{1}$ S. C. Tonon Da Luz, PhD; ${ }^{2}$ Rebeca Goya Este-

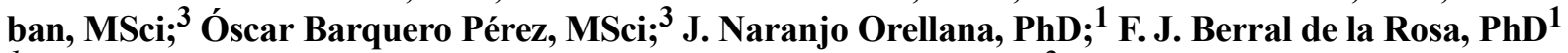 \\ ${ }^{1}$ Department of Sports, University Pablo de Olavide, Seville, Spain; ${ }^{2}$ Department of Physical Therapy, University of \\ Estado do Santa Katarina, Florianopolis, Brazil; ${ }^{3}$ Department of Signal Theory and Communications, University Rey \\ Juan Carlos, Fuenlabrada, Madrid, Spain
}

\begin{abstract}
Phantom-limb pain (PLP) is a phenomenon that may appear among people with amputation. Some studies reveal that $70 \%$ of people with amputation experience PLP years postamputation. There is a lack of scientific evidence about the cause of PLP. It has been hypothesized that the autonomic nervous system (ANS) could be involved in the mechanism that triggers PLP, but this hypothesis remains unclear. The aim of this study was to correlate ANS function, through heart rate variability (HRV) analysis, with PLP in adult males with amputation. The study population comprised 35 subjects, with 27 reporting PLP often or always. The rest of the subjects did not report any PLP. In order to calculate linear and nonlinear parameters of HRV, all subjects underwent $10 \mathrm{~min}$ of resting heart rate monitoring. The study did not find correlations between HRV parameters and PLP. Most of the subjects showed decreased values in linear parameters of HRV while nonlinear values were normal. HRV is not implicated in PLP. Linear and nonlinear methods for HRV analysis might reflect different physiological phenomena; while linear values place people with amputation at cardiovascular risk, nonlinear values indicate normality.
\end{abstract}

Key words: amputation, autonomic nervous system, cardiovascular risk, frequency domain parameters, heart rate variability, linear methods, location of residual limb, nonlinear methods, number of residual limbs, phantom-limb pain, physical activity.

\section{INTRODUCTION}

A large percentage of people with amputation report a persisting sensory awareness of the missing segment. This sensory awareness is called phantom limb (PL) and is usually described as a tingling or numb quality. When that PL sensation includes pain, it is called PL pain (PLP), which affects $>70$ percent of the population with amputation [1].

The causes that provoke PLP remain unclear. The literature comprises several reasons for developing PLP, but none seem feasible by themself. Hence, some authors are in favor of explaining this phenomenon by different etiological mechanisms [1-2]. Because the origin of PLP is not clear, $<10$ percent of patients are helped by physicianprescribed drugs for attenuating symptoms [1]. Among all the causes hypothesized as triggers of PLP, one relates to

\footnotetext{
Abbreviations: $\mathrm{ACI}=$ acceleration change index, $\mathrm{ANS}=$ autonomic nervous system, $\mathrm{CV}=$ cardiovascular, $\mathrm{HF}=$ highfrequency power, $\mathrm{HRV}=$ heart rate variability, $\mathrm{LF}=$ lowfrequency power, $\mathrm{PL}=$ phantom limb, PLP $=$ phantom-limb pain, RMSSD = root-mean-square differences of successive heartbeat intervals, SampEn = sample entropy.

*Address all correspondence to Elena Sarabia Cachadiña, PhD; Sor María Ángeles Querencio 9, 41970, Santiponce, Seville, Spain; +34-691197569. Email: elensarac@gmail.com http://dx.doi.org/10.1682/JRRD.2012.05.0079
} 
the autonomic nervous system (ANS). This cause is based on abnormal sympathetic activity on the residual limb, which affects sympathetic-efferent outflow of cutaneous vasoconstrictor fibers, skin temperature, and sympathetic impulse pattern [1,3-4] even in subjects without pain [4]. Moreover, Katz reports that increases in the intensity of PL paresthesiae follow bursts of sympathetic activity in the residual-limb neuromas while decreases correspond to periods of relative sympathetic activity [1].

Based on the literature, there is a lack of publications about heart rate variability (HRV) as a marker of ANS state in people with amputation. Perhaps applying HRV methods could help create a better understanding of the mechanisms involved in PLP.

$\mathrm{HRV}$ analysis is a noninvasive tool based on the calculation of time variations along consecutive heartbeats. It reflects cardiovascular (CV) responses to autonomic activity [5-9] and other physiological phenomena that do not originate in ANS. Reduced HRV parameters are related to CV risk, being the target issue of several investigations [7,10-11]. We applied linear and nonlinear methods for the analysis of HRV. Linear methods comprised frequencyand time-domain parameters. Frequency-domain analysis included high-frequency power (HF) and low-frequency power (LF). HF reflects solely parasympathetic activity, while LF reflects sympathetic and parasympathetic activity [11]. Because the role of LF is not well defined in the literature, its implication in the ANS is still controversial [7,11-13]. For time-domain analysis, we selected the root-mean-square differences of successive heartbeat intervals (RMSSD), which represents parasympathetic activity [11]. The nonlinear analysis of HRV included two fractal indexes and two indexes obtained from calculations based on the entropic characteristics of the signal. Fractal indexes are based in the analysis of the fractal properties of the signal and are represented by two slopes: $\alpha 1$ and $\alpha 2$
[14-15]. Normal values for fractal indexes must be close to 1 [14-15]. We expect that in pathological states the signal loses its fractal component, reflecting a loss of complexity of the system [16-17]. Sample entropy (SampEn) and acceleration change index (ACI) are based on the theory of entropy, and both quantify the irregularities among time series of signals [17-18]. Decreased SampEn values indicate physiological abnormalities [19], whereas decreased values of ACI (around 0.30) indicate normality [20].

Because HRV analysis contributes with a physiological approach of ANS function in order to find a mechanism that could be involved in PLP, the objective of this study was to explore HRV in people with amputation with and without PLP.

\section{METHODS}

We recruited 35 Spanish subjects with amputation from the Spanish peninsular territory. We divided them into two subgroups: PLP group (27 subjects who reported PLP) and no PLP group ( 8 subjects without PLP). Table 1 shows population demographics. We conducted all measurements under laboratory conditions in three cities $\left(24^{\circ} \mathrm{C}\right.$ between 10 a.m. and 6 p.m.). Only one city was located at sea level. The inclusion criteria for the PLP group were one amputated limb, adult, male, and experienced PLP often and close to the measurement day. For the no PLP group, the inclusion criteria were similar, except that these subjects had never experienced PLP. The exclusion criteria were medication and/or disease that would affect ANS function.

To perform HRV trials, we applied the standard protocol for resting laboratory measurements [11], where all subjects laid down for $20 \mathrm{~min}$ in a supine position without pillow or tilt and without prosthesis. The subjects

Table 1.

Participant demographics.

\begin{tabular}{|c|c|c|c|c|c|c|c|}
\hline \multirow{2}{*}{ Group } & \multirow{2}{*}{$n$} & \multirow{2}{*}{ Age (yr) ${ }^{*}$} & \multirow{2}{*}{ BMI* } & \multirow{2}{*}{$\operatorname{PA}(\mathbf{h} / \mathbf{w k})^{*}$} & \multicolumn{3}{|c|}{ Amputation Level (\%) } \\
\hline & & & & & 1 & 2 & 3 \\
\hline$\overline{\mathrm{PLP}}$ & 27 & $48.1 \pm 12.8$ & $27.7 \pm 4.1$ & $1.8 \pm 3.7$ & 25.92 & 59.25 & 14.81 \\
\hline No PLP & 8 & $41.1 \pm 9.6$ & $26.9 \pm 4.7$ & $0.8 \pm 1.5$ & 75.00 & 25.00 & - \\
\hline Total & 35 & $46.5 \pm 12.4$ & $27.6 \pm 4.3$ & $1.6 \pm 3.4$ & 37.14 & 51.42 & 11.42 \\
\hline
\end{tabular}

Note: Amputation level is composed of three different degrees of amputation: level $1=$ transtibial or transradial; level $2=$ transfemoral, shoulder or hip disarticulation, or two amputations of level 1; level 3 = amputation of level 2 plus amputation of level 1 .

${ }^{*}$ Mean \pm standard deviation.

$\mathrm{BMI}=$ body mass index, $\mathrm{PA}=$ physical activity, $\mathrm{PLP}=$ phantom-limb pain. 
underwent the trials $2 \mathrm{~h}$ after a meal; they also avoided ingesting stimulant substances and exercising $24 \mathrm{~h}$ prior testing.

A Heart Rate Monitor Firstbeat Bodyguard (Firstbeat Technologies Oy; Jyväskylä, Finland) recorded all heartbeat intervals (while subjects were in supine position) and performed data preprocessing. We selected the last $10 \mathrm{~min}$ of the recording for HRV analysis. For data postprocessing, there were two different pathways. First, Firstbeat Health Software (Firstbeat Technologies Oy) calculated linear parameters of HRV: RMSSD, LF (range: $0.04-0.15 \mathrm{~Hz}$ ), and $\mathrm{HF}$ (range: $0.15-1.00 \mathrm{~Hz}$ ). Second, from the R-R intervals (provided by the heart rate monitor), this research calculated nonlinear parameters of HRV: SampEn, ACI, $\alpha 1$, and $\alpha 2$. We calculated all nonlinear parameters following the pathways described in the literature [14-15,19,21].

In order to clarify whether ANS is implicated in PLP, we examined parasympathetic and sympathetic markers of HRV in the PLP and no PLP groups. Because of the non-normal distribution of the sample, we performed the statistical analysis using the nonparametric MannWhitney test. In addition, we analyzed the correlations among all HRV parameters and the rest of the variables, concentrating all subjects in the same group. Because of the characteristics of the sample, we used the Spearman correlation coefficient. We used SPSS software 319 (SPSS version 18.0, IBM Corporation; Armonk, New York) to perform all the statistical calculations.

\section{RESULTS}

We did not find differences in HRV between the PLP and no PLP groups. In both groups, RMSSD and HF were close to the border of the abnormality (normal values for RMSSD must be $>20 \mathrm{~ms}$ [22] while normal values for HF must be $>1,000 \mathrm{~ms}^{2}$ [23]). Nevertheless, LF was seriously decreased (normal values for this parameter must be $>1,000 \mathrm{~ms}^{2}$ [23]) (Table 2). HRV outcomes were independent of PLP, number of amputations, physical activity time, or residual-limb location.

Moreover, we found some interesting results from analyzing the correlations where LF was the only HRV parameter that did not correlate with the others (Table 3). The main correlation we found was between HF and RMSSD (Figure).

\section{DISCUSSION}

Our main finding was the absence of a link between PLP and HRV parameters, meaning that ANS, represented by HRV parameters, is not implicated in this phenomenon. However, several articles in the literature report an abnormal sympathetic [1,3,5] and parasympathetic [21] activity in the residual-limb region, even without reporting PLP [4]. Therefore, it seems that PLP is not a condition for developing abnormalities in ANS function. Perhaps this finding is the key to understanding the outcomes of our study: all subjects, independent of PLP or no PLP, showed decreased values in linear parameters of HRV, especially in LF (which is supposed to reflect sympathetic activity).

Regarding amputation characteristics, it could be hypothesized that this aspect could determine the magnitude of HRV values since it is possible that subjects at amputation level 3 (missing more than one limb) would have more reduced HRV parameters than those at amputation level 1 (transradial or transtibial amputation). In the present study, the number or location of amputations did not correlate with HRV; however, Modan et al. have related proximity and number of amputations to higher CV risk [24].

Table 2.

Heart rate variability parameters. Values are mean \pm standard deviation.

\begin{tabular}{lccccccc}
\hline Group & $\begin{array}{c}\text { SampEn } \\
(\boldsymbol{p}=\mathbf{0 . 5 6 )}\end{array}$ & $\begin{array}{c}\boldsymbol{\alpha 1} \\
(\boldsymbol{p}=\mathbf{0 . 8 3})\end{array}$ & $\begin{array}{c}\boldsymbol{\alpha 2} \\
(\boldsymbol{p}=\mathbf{0 . 9 7})\end{array}$ & $\begin{array}{c}\text { ACI } \\
(\boldsymbol{p}=\mathbf{0 . 7 2})\end{array}$ & $\begin{array}{c}\text { RMSSD (ms) } \\
(\boldsymbol{p}=\mathbf{0 . 5 7 )}\end{array}$ & $\begin{array}{c}\left.\text { LF (ms } \mathbf{2}^{\mathbf{2}}\right) \\
(\boldsymbol{p}=\mathbf{0 . 9 7})\end{array}$ & $\begin{array}{c}\text { HF (ms } \\
(\boldsymbol{p}=\mathbf{0 . 7 8})\end{array}$ \\
\hline PLP & $1.26 \pm 0.33$ & $1.19 \pm 0.26$ & $0.97 \pm 0.16$ & $0.31 \pm 0.12$ & $23 \pm 13$ & $30 \pm 25$ \\
No PLP & $1.31 \pm 0.34$ & $1.20 \pm 0.25$ & $0.92 \pm 0.12$ & $0.24 \pm 0.14$ & $26 \pm 23$ & $31 \pm 27$ & $1,257 \pm 1,855$ \\
Total & $1.27 \pm 0.33$ & $1.19 \pm 0.25$ & $0.96 \pm 0.15$ & $0.30 \pm 0.13$ & $24 \pm 15$ & $30 \pm 25$ & $889 \pm 1,034$ \\
\hline
\end{tabular}

Note: $p$-values show absence of significant differences among PLP and no PLP groups.

$\alpha 1=$ slope $1, \alpha 2=$ slope $2, \mathrm{ACI}=$ acceleration change index, $\mathrm{HF}=$ high-frequency power, $\mathrm{LF}=$ low-frequency power, $\mathrm{PLP}=$ phantom-limb pain, $\mathrm{RMSSD}=$ rootmean-square differences of successive heartbeat intervals, SampEn = sample entropy. 
Table 3.

Significant correlations.

\begin{tabular}{lcc}
\hline \multirow{2}{*}{ Variable } & \multicolumn{2}{c}{ Significant Correlation } \\
\cline { 2 - 3 } & \multicolumn{1}{c}{$\mathbf{1}$} & $\mathbf{2}$ \\
\hline SampEn & $\alpha 1(r=-0.585)^{*}$ & $\mathrm{RMSSD}(r=0.336)^{\dagger}$ \\
$\alpha 1$ & $\alpha 2(r=0.297)^{\dagger}$ & $\mathrm{HF}(r=-0.583)^{*}$ \\
$\alpha 2$ & $\mathrm{RMSSD}(r=-0.505)^{*}$ & $\mathrm{HF}(r=-0.518)^{*}$ \\
ACI & $\mathrm{RMSSD}(r=-0.297)^{\dagger}$ & $\mathrm{HF}(r=-0.419)^{*}$ \\
RMSSD & $\alpha 1(r=-0.604)^{*}$ & $\mathrm{HF}(r=0.961)^{*}$ \\
${ }^{*} p \leq 0.05$. & \\
${ }^{\dagger} p \leq 0.01$. & \\
$\alpha 1=$ slope $1, \alpha 2=$ slope 2, ACI $=$ acceleration change index, HF $=$ high- \\
frequency power, RMSSD $=$ root-mean-square differences of successive heart- \\
beat intervals, SampEn $=$ sample entropy.
\end{tabular}

Moreover, the absence of correlations between the LF component of HRV and the rest of the HRV variables measured in this study enhances the controversy supported by different authors about the role of this index in the ANS [7,25-26]. We expected the strong correlation between RMSSD and HF because it is already described in the literature [11]. Additionally, we found that SampEn correlated with RMSSD (a parasympathetic flow indicator [11]), whereas the rest of the nonlinear parameters showed an inverse association with RMSSD and HF. With respect to nonlinear outcomes, there is no support in the literature for a better understanding of what we found, but it seems that nonlinear methods of HRV reflect clearly different physiological phenomena than linear methods. Further research is needed for clarifying the physiological role of nonlinear values, because this lack of knowledge gives more scientific relevance to linear than to nonlinear parameters in the present study.

Finally, one more aspect of this study is difficult to solve. While linear parameters of HRV were decreased, indicating $\mathrm{CV}$ risk, nonlinear values remained normal. In this case, it is interesting that much of the literature reports CV risk factors in people with amputation [2730]. Thus, the linear outcomes of our study are supported by other investigations, which have estimated $\mathrm{CV}$ risk factors using different parameters.

For further clinical and rehabilitation interventions, we highly recommend promoting $\mathrm{CV}$ risk prevention programs among the amputee population. We also recommend including HRV analysis and physical activity in these programs [31].

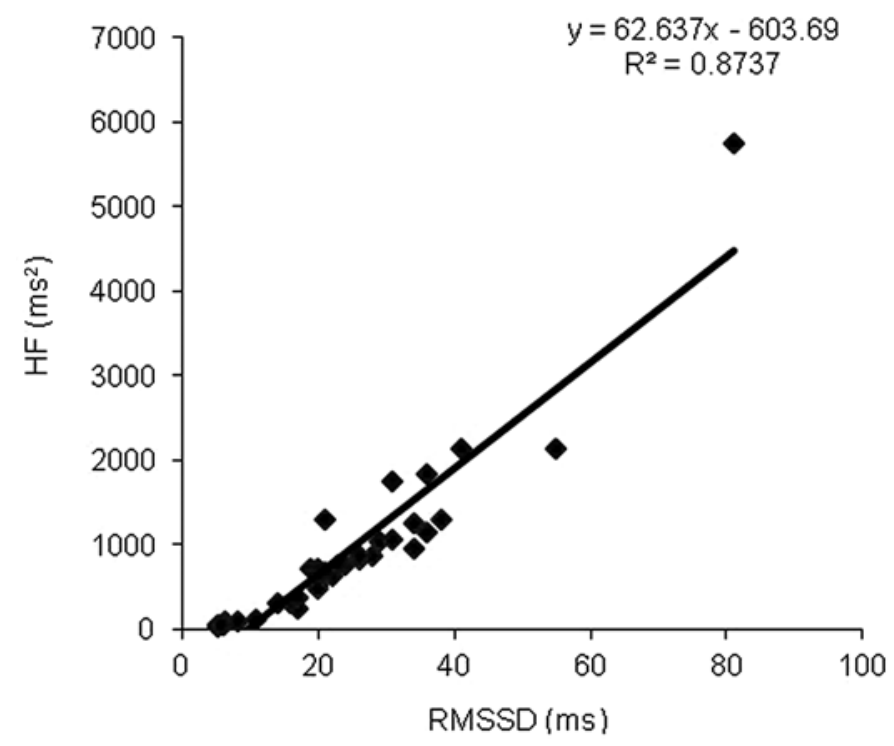

Figure.

Dispersion plot of high-frequency power (HF) of heart rate variability and root-mean-square differences of successive heartbeat intervals (RMSSD) correlation.

\section{CONCLUSIONS}

HRV is not implicated in PLP. Physical activity, number of amputations, or residual-limb location does not determine the magnitude of HRV parameters. Additionally, linear and nonlinear methods for HRV analysis might reflect different physiological phenomena; while linear values place people with amputation with and without PLP at CV risk, nonlinear values remain normal. In brief, having one amputation with or without PLP is reason enough for the drop of linear parameters of HRV.

\section{ACKNOWLEDGMENTS}

\section{Author Contributions:}

Study concept and design: E. Sarabia Cachadiña, J. Naranjo Orellana, F. J. Berral de la Rosa.

Acquisition of data: P. Granados García, E. Sarabia Cachadiña,

S. C. Tonon Da Luz.

Analysis and interpretation of data: E. Sarabia Cachadiña, P. Granados García, R. Goya Estaban, Ó. Barquero Pérez.

Drafting of manuscript: E. Sarabia Cachadiña.

Critical revision of manuscript for important intellectual content:

J. Naranjo Orellana.

Statistical analysis: E. Sarabia Cachadiña.

Obtained funding: F. J. Berral de la Rosa.

Study supervision: J. Naranjo Orellana, F. J. Berral de la Rosa. 
Financial Disclosures: The authors have declared that no competing interests exist.

Funding/Support: This material is based on work supported by Foundation Mapfre-Spain, Spanish National Association of Amputees, University of Estado do Santa Katarina, University Pablo de Olavide, and Firstbeat Techonologies Oy. The Spanish Education Ministry has financed Óscar Barquero Pérez with a Faculty Training Scholarship (AP2009-1726).

Additional Contributions: We would especially like to acknowledge the experimental subjects that made this study possible and Cristina Blasco Lafarga, Nacho Martínez Navarro, and Míkel Zabala for their scientific contribution to this investigation. Dr. Sarabia Cachadiña and Mr. Granados García are now with Researching Group CTS 595: High Performance, Health, and Sport, Junta de Andalucía, Spain.

Institutional Review: All subjects signed an informed written consent and all processes for developing this research followed the Declaration of Helsinki. University Pablo de Olavide approved the procedures for developing this research.

Participant Follow-up: Our group is in contact with all associations that provided subjects. We will inform them about the publication of this study.

\section{REFERENCES}

1. Katz JJ. Psychophysical correlates of phantom limb experience. J Neurol Neurosurg Psychiatry. 1992;55(9):811-21. [PMID:1402973] http://dx.doi.org/10.1136/jnnp.55.9.811

2. Sherman RA, Arena JG, Sherman CJ, Ernst JL. The mystery of phantom pain: growing evidence for psychophysiological mechanisms. Biofeedback Self Regul. 1989;14(4): 267-80. [PMID:2698750] http://dx.doi.org/10.1007/BF00999118

3. Harden RN, Gagnon CM, Gallizzi M, Khan AS, Newman D. Residual limbs of amputees are significantly cooler than contralateral intact limbs. Pain Pract. 2008;8(5):342-47. [PMID:18513229] http://dx.doi.org/10.1111/j.1533-2500.2008.00216.x

4. Fagius JJ, Nordin MM, Wall MM. Sympathetic nerve activity to amputated lower leg in humans. Evidence of altered skin vasoconstrictor discharge. Pain. 2002;98(1-2):37-45. [PMID:12098615] http://dx.doi.org/10.1016/S0304-3959(01)00466-3

5. Katz JJ. Psychophysiological contributions to phantom limbs. Can J Psychiatry. 1992;37(5):282-98. [PMID:1638452]

6. Aubert AE, Seps B, Beckers F. Heart rate variability in athletes. Sports Med. 2003;33(12):889-919. [PMID:12974657] http://dx.doi.org/10.2165/00007256-200333120-00003

7. Dewey FE, Freeman JV, Engel G, Oviedo R, Abrol N, Ahmed N, Myers J, Froelicher VF. Novel predictor of prognosis from exercise stress testing: heart rate variability response to the exercise treadmill test. Am Heart J. 2007;
153(2):281-88. [PMID:17239690]

http://dx.doi.org/10.1016/j.ahj.2006.11.001

8. Gallo JA, Farbiarz J, Álvarez DL. Análisis espectral de la variabilidad de la frecuencia cardíaca. Iatreia. 1999;12(2): 94-104. Spanish.

9. Cabrera Rojo I, Cabrera Santos A, Gallardo Montes de Oca G. Variabilidad de la frecuencia cardíaca en el joven normal. Rev Cub Invest Bioméd. 1997;16(2):98-103. Spanish.

10. Ng F, Wong S, La Cruz A, Hernández MI, Gomis P, Passariello G. Heart rate recovery in the diagnosis of diabetic Cardiovascular Autonomic Neuropathy. Proceedings of the 2007 Computers in Cardiology Conference; 2007 Sep 30-Oct 3; Durham, NC. p. 681-84.

11. Heart rate variability: standards of measurement, physiological interpretation and clinical use. Task Force of the European Society of Cardiology and the North American Society of Pacing and Electrophysiology. Circulation. 1996;93(5): 1043-65. [PMID:8598068] http://dx.doi.org/10.1161/01.CIR.93.5.1043

12. Leicht AS, Hirning DA, Allen GD. Heart rate variability and endogenous sex hormones during the menstrual cycle in young women. Exp Physiol. 2003;88(3):441-46. [PMID:12719769] http://dx.doi.org/10.1113/eph8802535

13. Perini R, Veicsteinas A. Heart rate variability and autonomic activity at rest and during exercise in various physiological conditions. Eur J Appl Physiol. 2003;90(3-4):317-25.

[PMID:13680241] http://dx.doi.org/10.1007/s00421-003-0953-9

14. Peng CK, Havlin SS, Stanley HE, Goldberger AL. Quantification of scaling exponents and crossover phenomena in nonstationary heartbeat time series. Chaos. 1995;5(1):82-87. [PMID:11538314] http://dx.doi.org/10.1063/1.166141

15. Kantelhardt JW, Zschiegner SA, Koscielny-Bunde E, Havlin S, Bunde A, Stanley HE. Multifractal detrended fluctuation analysis of nonstationary time series. Physica A. 2002; 316(1-4):87-114. http://dx.doi.org/10.1016/S0378-4371(02)01383-3

16. Goldberger AL, Amaral LA, Glass L, Hausdorff JM, Ivanov PC, Mark RG, Mietus JE, Moody GB, Peng CK, Stanley HE. PhysioBank, PhysioToolkit, and PhysioNet: components of a new research resource for complex physiologic signals. Circulation. 2000;101(23):E215-20. [PMID:10851218] http://dx.doi.org/10.1161/01.CIR.101.23.e215

17. Bernaola-Galván P, Ivanov PC, Nunes Amaral LA, Stanley HE. Scale invariance in the nonstationarity of human heart rate. Phys Rev Lett. 2001;87(16):168105.

[PMID:11690251] http://dx.doi.org/10.1103/PhysRevLett.87.168105

18. Ferrario M, Signorini MG, Magenes G, Cerutti S. Comparison of entropy-based regularity estimators: application to 
the fetal heart rate signal for the identification of fetal distress. IEEE Trans Biomed Eng. 2006;53(1):119-25.

[PMID:16402611]

http://dx.doi.org/10.1109/TBME.2005.859809

19. Richman JS, Moorman JR. Physiological time-series analysis using approximate entropy and sample entropy. Am J Physiol Heart Circ Physiol. 2000;278(6):H2039-49. [PMID:10843903]

20. Schuckers SA, Raphisak P. Distinction of arrhythmias with the use of approximate entropy. Proceedings of the 1999 Computers in Cardiology Conference; 1999 Sep 26-29; Hanover, Germany. p. 347-50.

21. García-González MA, Ramos-Castro J, Fernández-Chimeno M. A new index for the analysis of heart rate variability dynamics: characterization and application. Physiol Meas. 2003;24(4):819-32. [PMID:14658775] http://dx.doi.org/10.1088/0967-3334/24/4/301

22. Zulfiqar U, Jurivich DA, Gao W, Singer DH. Relation of high heart rate variability to healthy longevity. Am J Cardiol. 2010;105(8):1181-85. [PMID:20381674] http://dx.doi.org/10.1016/j.amjcard.2009.12.022

23. Corrales MM, de la Cruz Torres B, Esquival AG, Salazar MA, Orellana JN. Normal values of heart rate variability at rest in a young, healthy and active Mexican population. Health. 2012;4(7):377-85. http://dx.doi.org/10.4236/health.2012.47060

24. Modan M, Peles E, Halkin H, Nitzan H, Azaria M, Gitel S, Dolfin D, Modan B. Increased cardiovascular disease mortality rates in traumatic lower limb amputees. Am J Cardiol. 1998;82(10):1242-47. [PMID:9832102] http://dx.doi.org/10.1016/S0002-9149(98)00601-8

25. Cachadiña ME, Wadén J, Uusitalo A, Peltonen JE, Rosengård-Bärlund $\mathrm{M}$, Groop $\mathrm{PH}$, Heikki $\mathrm{O}$. Acute exercise effects on heart rate variability and heart rate recovery in type 1 diabetes. Med Sci Sports Exerc. 2009;41(5):68.

26. Sarabia Cachadiña E. Heart rate variability: Applications for clinical diagnosis and sports performance [doctoral thesis]. [Seville (Spain)]: University Pablo de Olavide, Faculty of Sports; 2012.

27. Naschitz JE, Lenger RR. Why traumatic leg amputees are at increased risk for cardiovascular diseases. QJM. 2008;
101(4):251-59. [PMID:18281705]

http://dx.doi.org/10.1093/qjmed/hcm131

28. Mozumdar AA, Roy SK. Somatotype of the individuals with lower extremity amputation and its association with cardiovascular risk. Anthropol Anz. 2008;66(1):99-116. [PMID:18435209]

29. Frugoli BA, Guion KW, Joyner BA, MacMillan JL. Cardiovascular disease risk factors in an amputee population. J Prosthet Orthot. 2000;12(3):80-87.

http://dx.doi.org/10.1097/00008526-200012030-00004

30. Shahriar SH, Masumi MM, Edjtehadi FF, Soroush MR, Soveid MM, Mousavi BB. Cardiovascular risk factors among males with war-related bilateral lower limb amputation. Mil Med. 2009;174(10):1108-12. [PMID:19891226]

31. Korkmaz A. The physiological effects of sports in amputees. NATO ASI Ser E Hum Soc Dyn. 2007;31:48-64.

Submitted for publication May 7, 2012. Accepted in revised form August 27, 2012.

This article and any supplementary material should be cited as follows:

Sarabia Cachadiña E, Granados García P, Tonon Da Luz SC, Goya Esteban R, Barquero Pérez Ó, Naranjo Orellana J, Berral de la Rosa FJ. Heart rate variability and phantom pain in male amputees: Application of linear and nonlinear methods. J Rehabil Res Dev. 2013;50(3): 449-54.

http://dx.doi.org/10.1682/JRRD.2012.05.0079

ResearcherID/ORCID: Elena Sarabia Cachadiña, PhD: C-6413-2013; Pablo Granados García, MSci: C-6601-2013; Rebeca Goya Esteban, MSci: C-6409-2013; Óscar Barquero Pérez, MSci: C-6425-2013; J. Naranjo Orellana, PhD: C-6544-2013; F. J. Berral de la Rosa, PhD: C-6553-2013

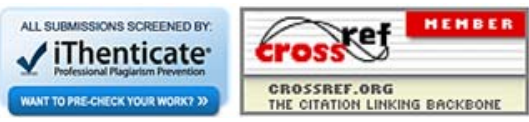

